\title{
ANALISIS MATERI POKOK SENI BUDAYA DAN PRAKARYA (SBdP) KELAS III MI/SD
}

\section{ANALYSIS OF THE SUBJECT MATTER OF ART AND CULTURE AT THE THIRD GRADE OF ELEMENTARY SCHOOL}

\author{
Siti Pitriani \\ Fakultas Ilmu Tarbiyah dan Keguruan UIN Sunan Kalijaga Yogyakarta \\ Jalan Marsda Adicipto Yogyakarta \\ Email: $19204080001 @$ student.uin-suka.ac.id
}

Submitted: 25-12-2019, Revised: 11-06-2020, Accepted: 15-06-2020

\begin{abstract}
Abstrak
Penelitian ini bertujuan untuk mengetahui relevansi antara materi pokok y ang terdapat pada buku tematik guru dan siswa kelas III kurikulum 2013 revisi 2018 dengan ruang lingkup materi pokok seni budaya dan prakarya (SBdP) MI/SD yang mencakup kompetensi pengetahuan dan keterampilan, karakteris tik dan perkembang an materi SBdP MI/SD, analis is KI-KD dan relevansinya deng an struktur keilmuan SBdP MI/SD, karakteristik perkembangan siswa, HOTS, 4C (critical thinking, creativity, communication, collaboration), literasibudaya dan kewargaan, pendidikan karakter, dan inovasi. Metode penelitian yang digunakan adalah jenis penelitian studi pustaka. Pengumpulan dan peninjauan indikator referensi untuk analis is materi pokok SBdP MI kelas III SD/MI. Hasil analisis menyatakan bahwa relevansi ruang lingkup SBdP dalamPermendikbud nomor 21 tahun 2016 tentang standar isi pendidikan das ar dan menengah dengan buku sis wa kurikulum 2013 revisi 2018 dinilai sudah relevan. Karakteristik SBdP MI/SD mencakup aspek seni rupa, seni musik, seni tari, dan keterampilan. Karakteristik perkembang an siswa berada dalamtahap oprasional konkrit. HOTS, 4C, literasi budaya dan kewargaan, serta pendidikan karakter tercantumpada materi pokok SBdP revisi 2018 buku paket guru dan siswa kelas III. Inovasi yang ditawarkan dalam pembelajaran SBdP MI/SD adalah meng gunakan multimedia interaktif yang relevan dengan perkembangan ilmu pengetahuan dan teknologi diera revolusi industri 4.0.
\end{abstract}

Kata Kunci: Analisis, Materi Pokok, Seni Budaya dan Prakarya, MI/SD

\begin{abstract}
This research aimed to find out the relevance between the subject matter of the teachers' and the students' thematic book based on 2013 curriculum revised 2018 and the subject matter scope of art and culture (SBdB) in the $3^{\text {rd }}$ grade of elementary school (MI/SD) which included knowledge and skills, characteristics and developments of the subjectmaterials, analysis of the core and base competencies (KI-KD) and their relevance to the subject structure, characteristics of students' development, HOTS, $4 \mathrm{C}$ (critical thinking, creativity, communication, collaboration), cultural and citizenship literacy, character education, and innovation. The method used wa s library research. Collecting and reviewing the reference indicators were done to analyze the subject matter of art and culture subject of the $3^{\text {rd }}$ grade students at elementary school. The results indicated that SBdB scope based on Indonesian Ministry of Education and Culture (Permendikbud) No. 21 in 2016 on the content standards ofbasic and secondaryeducation with the students' book based on 2013 curriculum revised 2018 was considered relevant. Characteristics of art and culture subject consisted offine arts, music, dance, and skill aspects. Characteristics of the students' development were in a concrete operational stage. HOTS, $4 C$, cultural and citizenship literacy, and character education were listed in the teachers' and the students' thematic book based on 2013 curriculum revised 2018 in the $3^{\text {rd }}$ grade of MI/SD. The innovation offered in teaching art and culture subject at MI/SD was to use interactive multimedia that was relevant to the development of science and technology in the industrial revolution era 4.0.
\end{abstract}

Keywords: Analysis, Subject Matter, Art and Culture, MI/SD 
How to Cite: Pitriani, S. (2020). Analisis Materi Pokok Seni Budaya dan Prakarya (SBdP) Kelas III MI/SD. AULADUNA: Jurnal Pendidikan Dasar Islam, 7(1), 60-73.

\section{Pendahuluan}

Tiga kraton Jawa yang masih berpengaruh hingga kini yakni kraton Yogyakarta, kraton Surakarta, dan kraton Cirebon yang biasanya masih menyelenggarakan budaya sekaten hingga sebulan penuh. Hal ini menjadi bukti terdapatnya pengaruh budaya dengan peradaban bangsa, bahkan agama Islam masuk dalam nusantara melalui akulturasi seni dan budaya. Tradisi yang telah ada pada masa lalu tidak serta merta dihilangkan begitu saja, namun para wali memasukkan nilai-nilai Islam ke dalam tradisi dan kebudayaan masyarakat nusantara. Seni budaya memberikan pengaruh yang sangat besar dalam kehidupan bermasyarakat, oleh karena itu sejak pendidikan kurikulum pendidikan di Indonesia juga mencantumkan seni budaya dan prakarya (Sutiyono, 2010: 9).

Seni budaya dan prakarya yang sering disingkat dengan SBdP merupakan salah satu materi pokok yang diwajibkan dalam kurikulum 2013. Beberapa aspek di dalamnya meliputi aspek seni rupa, seni musik, seni tari, dan keterampilan. Materi pokok dalam SBdP bukan hanya sekedar materi namun juga terdapat bagian yang memiliki andil dalam pembentukan kepribadian seorang anak sebagai dasar dalam pembentukan akhlak terpuji dan keperibadian yang baik. Fungsi dan tujuan SBdP yaitu dapat mengembangkan sikap siswa, kemampuan yang dimiliki siswa, dan semangat daam berkarya, sehingga menciptakan generasi-generasi yang kreatif dan mampu berpikir kritis dalam menghadapi era digital ini (Muin, 2017: 133-135).

Materi yang disajikan dalam SBdP juga bervariasi sehingga akan didapatkan berbagai macam kecerdasan yang bisa diperoleh anak, seperti kecerdasan dalam memahami diri sendiri, kecerdasan berimajinasi, kecerdasan bermusik, dan kecerdasan berbahasa. Berbicara tentang kecerdasan, seseorang yang memiliki keterampilan berpikir mampu mengaplikasikan pengetahuannya untuk menyelesaikan permasalahan yang ada. Selain itu, siswa memerlukan kemampuan untuk berpikir tingkat tinggi agar mampu menyelesaikan permasalahan sehari-hari.

Siswa yang berkemampuan berpikir tingkat tinggi dapat berpikir kritis. Sehingga dapat menyelesaikan masalah, berani mengambil keputusan, dan mampu berpikir reflektif (Snyder \& Wiles, 2015). Sejalan dengan hal tersebut, Newman dan Wehlage dalam Mislia, Indartono, \& Mallisa (2018) juga mengatakan bahwa siswa yang memiliki keterampilan berpikir tingkat tinggi dapat membedakan ide atau pendapat dengan jelas, berani berdebat dengan baik, memiliki kemampuan menyelesaikan masalah, memiliki banyak ide kreatif, selalu berusaha mencari solusi untuk suatu masalah, dan mampu membangun penjelasan, serta mampu berhipotesis dan memahami hal-hal rumit menjadi lebih jelas. Berdasarkan hal tersebut, maka perlu dilakukan analisis secara mendalam tentang materi dalam SBdP yang disajikan kepada siswa dengan kebutuhan mereka, khususnya kemampuan berpikir tingkat tinggi.

Pada abad ini, perkembangan teknologi dan informasi sangat memberikan pengaruh yang besar bagi manusia. Kompetensi untuk hidup layak bergantung pada keterampilan-keterampilan yang dibutuhkan pada abad ini, diantaranya adalah berpikir kritis, kreativitas, berkolaborasi, dan berkomunikasi (Sani, 2019: 52). Hal ini yang menyebabkan perlunya menganalisis materi dalam SBdP yang disajikan kepada siswa 
untuk mengetahui sudah sesuai atau tidak dengan kebutuhan pada abad ini, terutama dalam kemampuan berpikir kritis, kreativitas, berkolaborasi, dan berkomunikasi.

Kehidupan masyarakat pada era saat ini ditandai oleh perkembangan ilmu pengetahuan, seni, dan teknologi yang menuntut masyarakat agar memiliki kemampuan dasar agar dapat bertahan hidup, kemampuan dasar itu disebut juga dengan literasi dasar (Yusuf \& Hayat, 2010: 24). Literasi dasar sangat ditekankan oleh pemerintah karena mengikuti tuntutan zaman, literasi dasar yang dimaksud meliputi literasi baca-tulis, literasi numerasi, literasi sains, literasi digital, dan literasi finansial, serta literasi budaya dan kewargaan. Tak ketinggalan pula pendidikan karakter yang terus disuarakan agar dapat membentuk pribadi yang cerdas serta berakhlaqul karimah. Sehingga, perlu dilakukan analisis untuk mengetahui sudah termuat atau belum semua aspek tersebut dalam materi pokok SBdP.

Permasalahan-permasalahan yang timbul dalam pembelajaran SBdP yaitu tidak semua siswa menaruh perhatian atau minat terhadap materi, kesulitan siswa dalam pemahaman materi yang telah diajarkan, dan kurangnya pengelolaan waktu yang baik, serta tidak semua latar belakang guru pengampu mumpuni dalam hal seni budaya dan prakarya.

Berdasarkan paparan di atas, penulis merasa perlu melakukan kajian analisis materi pokok SBdP secara mendalam dan terperinci untuk mengetahui materi yang diberikan guru sudah layak dikonsumsi oleh siswa atau belum, sudah sesuai dengan tuntunan kebutuhan zaman saat ini atau belum, dan inovasi dalam pembelajaran seni budaya dan prakarya masa kini.

\section{Metode Penelitian}

Penelitian ini menggunakan metode penelitian kepustakaan (library research) yaitu penelitian yang dilakukan di perpustakaan yang berupa buku-buku ilmiah dan tulisan-tulisan yang berhubungan dengan pembahasan yang sedang dilakukan. Studi kepustakaan merupakan kajian teoritis, referensi, dan literatur ilmiah lainnya yang berkaitan dengan budaya dan nilai serta norma yang berkembang pada situasi sosial yang diteliti untuk memperoleh kebenaran yang empirik pula. Data yang digunakan dalam penelitian ini berupa data sekunder, yaitu buku tematik guru dan siswa kelas III revisi 2018, buku-buku yang berkaitan dengan materi yang sedang diteliti, dan dokumen-dokumen tertulis. Selain itu, digunakan juga artikel-artikel yang diambil dari jurnal nasional.

\section{Hasil dan Pembahas an}

\subsection{Substansi dan Ruang Lingkup Materi Pokok Kelas III SD/MI}

Pendidikan SBdP diberikan di sekolah karena keunikan, kebermaknaan, dan kebermanfaatannya terhadap kebutuhan perkembangan siswa, yang terletak pada pemberian pengalaman estetik dalam bentuk kegiatan berekspresi/berkreasi dan berapresiasi melalui pendekatan belajar dengan seni dan belajar tentang seni. Peran ini tidak dapat diberikan oleh mata pelajaran lain (Hendriani, 2016: 112).

Mata pelajaran SBdP bertujuan untuk meletakkan dasar kecerdasan, pengetahuan, keperibadian, dan akhlak mulia, serta keterampilan untuk hidup mandiri dan mengikuti pendidikan lebih lanjut. Mata pelajaran SBdP bertujuan agar siswa memiliki kemampuan, yaitu memahami konsep dan pentingnya SBdP, menampilkan sikap apresiasi terhadap SBdP, menampilkan kreativitas melalui SBdP, dan 
menampilkan peran serta dalam SBdP dalam tingkat lokal, regional, maupun global (Hendriani, 2016: 112).

SBdP menjadi salah satu mata pelajaran yang dipelajari di jenjang pendidikan dasar. Semenjak diterapkannya kurikulum 2013, SBdP diintegrasikan dengan mata pelajaran lain dan tidak berdiri sendiri sebagai satu mata pelajaran. Menurut Permendikbud nomor 21 tahun 2016 tentang standar isi pendidikan dasar dan menengah, ruang lingkup materi SBdP MI/SD adalah sebagai berikut: (1) kreasi dan apresiasi karya seni rupa, (2) kreasi dan apresiasi karya seni musik, (3) kreasi dan apresiasi karya seni tari, dan (4) apresiasi dan kreasi prakarya (Kemendikbud, 2016).

Analisis ruang lingkup materi SBdP MI/SD kelas III tema 1 sampai tema 8 dijabarkan pada tabel berikut:

Tabel 1. Analisis Kesesuaian Materi Buku Tematik Kelas III dengan Permendikbud No.

21 Tahun 2016

\begin{tabular}{|c|c|c|c|c|c|}
\hline Tema & Sub Tema & Pembelajaran & Materi & Ruang Lingkup & HIm \\
\hline \multirow{4}{*}{1} & 1 & 1 dan 3 & $\mathrm{~A} 1, \mathrm{~B} 1$ & $\mathrm{~B}$ & $3-4,26-27$ \\
\hline & 2 & 1 dan 3 & $\mathrm{C} 1$ & $\mathrm{C}$ & $55-58,68-69$ \\
\hline & 3 & 1 dan 3 & $\mathrm{D} 1, \mathrm{E} 1$ & $\bar{A}$ & $100-102,116-117$ \\
\hline & 4 & 1 dan 3 & $\mathrm{~F} 1, \mathrm{G} 1$ & $\bar{D}$ & $147-148,163$ \\
\hline \multirow{4}{*}{2} & 1 & 1 dan 3 & $\mathrm{~A} 2, \mathrm{~B} 2$ & B & 9,20 \\
\hline & 2 & 1 dan 3 & $\mathrm{C} 2$ & $\bar{C}$ & $63-64,74$ \\
\hline & 3 & 1 dan 3 & $\overline{\mathrm{D} 2}$ & $\bar{A}$ & 118,133 \\
\hline & 4 & 1 dan 3 & $\mathrm{E} 2, \mathrm{~F} 2$ & $\bar{D}$ & $165,177-178$ \\
\hline \multirow{4}{*}{3} & 1 & 1 dan 3 & $\mathrm{~A} 3, \mathrm{~B} 3$ & $\mathrm{~B}$ & $8-10,27-28$ \\
\hline & 2 & 1 dan 3 & $\mathrm{C} 3$ & $\mathrm{C}$ & $68-69,87$ \\
\hline & 3 & 1 dan 3 & D3, E3 & A & $130,145-146$ \\
\hline & 4 & 1 dan 3 & $\bar{F} 3$ & $\mathrm{D}$ & $183-184,207-208$ \\
\hline \multirow{4}{*}{4} & 1 & 1 dan 3 & A4 & B & $6-9,24$ \\
\hline & 2 & 1 dan 3 & $\mathrm{~B} 4, \mathrm{C} 4$ & $\mathrm{C}$ & $52-55,65-66$ \\
\hline & 3 & 1 dan 3 & $\mathrm{D} 4, \mathrm{E} 4$ & $\bar{A}$ & $100-103,114-116$ \\
\hline & 4 & 1 dan 3 & $\mathrm{~F} 4$ & $\mathrm{D}$ & $143-144,156-157$ \\
\hline \multirow{4}{*}{5} & 1 & 1 dan 3 & A5, B5 & $\mathrm{B}$ & $9-10,24-25$ \\
\hline & 2 & 1 dan 3 & $\mathrm{C} 5$ & $\mathrm{C}$ & $57-60,83-85$ \\
\hline & 3 & 1 dan 3 & D5 & $\bar{A}$ & $128-130,144-145$ \\
\hline & 4 & 1 dan 3 & E5 & $\mathrm{D}$ & $185-187,201-203$ \\
\hline \multirow{4}{*}{6} & 1 & 1 dan 3 & A6, B6 & $\mathrm{B}$ & $6-8,28-30$ \\
\hline & 2 & 1 dan 3 & C6 & $\mathrm{C}$ & 58-60, 76-78 \\
\hline & 3 & 1 dan 3 & D6, E6 & $\overline{\mathrm{A}}$ & $107-109,124$ \\
\hline & 4 & 1 dan 3 & F6 & $\mathrm{D}$ & 155-157, 169-171 \\
\hline \multirow{4}{*}{7} & 1 & 1 dan 3 & A7, B7 & $\mathrm{B}$ & $3-5,24-25$ \\
\hline & 2 & 1 dan 3 & $\mathrm{C} 7$ & $\mathrm{C}$ & $70-73,88$ \\
\hline & 3 & 1 dan 3 & D7, E7 & $\bar{A}$ & $121-122,136-139$ \\
\hline & 4 & 1 dan 3 & $\overline{\text { F7 }}$ & $\mathrm{D}$ & $173-175,188-190$ \\
\hline \multirow{4}{*}{8} & 1 & 1 dan 3 & A8 & $\mathrm{B}$ & $2-4,21-23$ \\
\hline & 2 & 1 dan 3 & $\overline{\mathrm{B} 8}$ & $\mathrm{C}$ & $60-63,80-82$ \\
\hline & 3 & 1 dan 3 & $\mathrm{C} 8$ & $\overline{\mathrm{A}}$ & $118-120,133-134$ \\
\hline & 4 & 1 dan 3 & $\overline{\mathrm{D} 8}$ & $\bar{D}$ & 168-169, 187 \\
\hline
\end{tabular}


Hasil analisis ruang lingkup materi SBdP MI/SD menurut Permendikbud nomor 21 tahun 2016 dapat ditarik satu garis besar bahwa semua materi ruang lingkup sudah disampaikan di jenjang MI/SD kelas III sesuai dengan kegiatan pembelajaran dan kompetensi yang ingin dikembangkan. Presentase pemenuhan ruang lingkup materi SBdP MI/SD kelas III dapat dilihat pada gambar berikut:

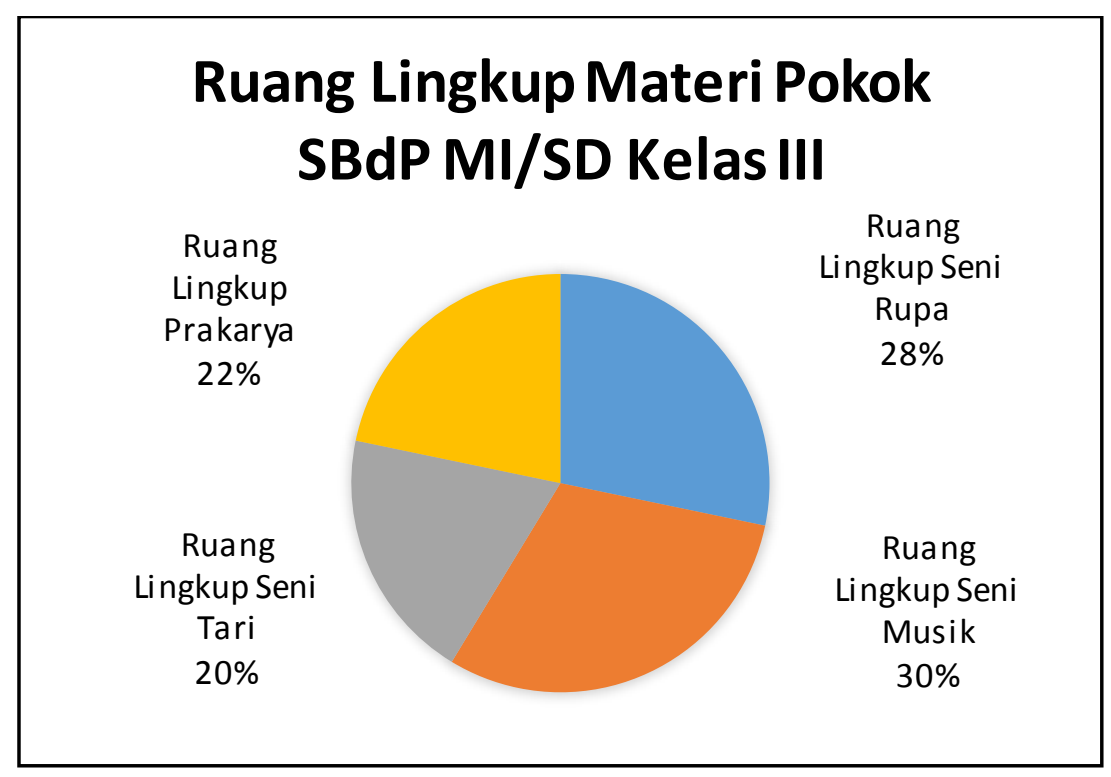

Gambar 1. Diagram Lingkaran Kategori Ruang Lingkup Materi SBdP Kelas III

Berdasarkan data tersebut, dapat disimpulan bahwa distribusi ruang lingkup SBdP dalam buku guru dan buku siswa kelas III adalah kreasi dan apresiasi karya seni rupa (a) 28\%, kreasi dan apresiasi karya seni musik (b) 30\%, kreasi dan apresiasi karya seni tari (c) $20 \%$, dan apresiasi dan kreasi prakarya (d) $22 \%$.

Dari gambar 1, diketahui bahwa semua materi telah merujuk kepada standar isi Permendikbud nomor 21 tahun 2016, maka buku bahan ajar tematik (buku guru dan buku siswa) telah relevan atau telah memenuhi ruang lingkup materi yang tercantum dalam Permendikbud nomor 21 tahun 2016.

\subsection{Karakteris tik dan Perkembangan Materi Pokok SBdP MI/SD}

Pada kurikulum 2013, dalam mata pelajaran SBdP, terdapat beberapa karakteristik terkait perkembangan materi SBdP MI/SD. Pertama, karakteristik dilihat dari aspek materi pokok. Beberapa aspek dalam materi pokok SBdP yakni: (1) seni rupa, meliputi keterampilan, nilai, dan pengetahuan dalam menciptakan karya seni berupa ukiran, lukisan, patung, dan lainnya, (2) seni musik, meliputi kemampuan dalam menguasai olah suara serta kemampuan dalam menggunakan alat musik, (3) seni tari, meliputi keterampilan gerak dengan memadukan antara audio, tari, dan rasa, serta apresiasi terhadap tarian-tarian, (4) seni drama, meliputi keterampilan dalam memadukan seni musik, seni tari, dan seni rupa dalam pementasan, dan (5) keterampilan, meliputi keterampilan dalam kecakapan hidup (Mulyani, 2016: 30).

Kedua, karakteristik perkembangan dan implikasinya dengan pengajaran seni. Karakteristik perkembangan dan implikasinya dengan pengajaran seni siswa kelas 3 dijabarkan oleh Hendriani (2016: 119) pada tabel berikut: 
Tabel 2. Kategori Karakteristik Perkembangan dan Implikasinya dengan Pengajaran Seni

\begin{tabular}{|c|c|c|}
\hline No. & $\begin{array}{c}\text { Karakte ristik Perkembangan pada } \\
\text { Kelas } 3 \\
\end{array}$ & Implikasi bagi Pengajaran Seni \\
\hline 1 & $\begin{array}{l}\text { Koordinasi mata dan tangan telah } \\
\text { terimprovisasi. }\end{array}$ & $\begin{array}{l}\text { Siswa akan menggambar bentuk kawan } \\
\text { sebaya sebagai model. }\end{array}$ \\
\hline 2 & $\begin{array}{l}\text { Penggunaan otot kecil telah lebih } \\
\text { baik. }\end{array}$ & Siswa akan menggambar pakaian. \\
\hline 3 & $\begin{array}{l}\text { Menjadi sadar akan perbedaan tiap } \\
\text { orang. }\end{array}$ & $\begin{array}{l}\text { Siswa akan menunjukkan perbedaan } \\
\text { antara gambar figure (sosok) } \\
\text { dalam karya mereka. }\end{array}$ \\
\hline 4 & $\begin{array}{l}\text { Secara umum pembelajaran menjadi } \\
\text { responsif, teratur, dan kerjasama. }\end{array}$ & $\begin{array}{l}\text { Siswa akan tukar pengalaman, } \\
\text { membagikan, dan mengumpulkan materi } \\
\text { seni. }\end{array}$ \\
\hline 5 & $\begin{array}{l}\text { Sudah mulai memisahkan bentuk } \\
\text { berdasarkan jenis kelamin. }\end{array}$ & $\begin{array}{l}\text { Memberikan motivasi berkarya bagi } \\
\text { siswa laki-laki dan perempuan } \\
\text { berdasarkan minatnya. }\end{array}$ \\
\hline 6 & $\begin{array}{l}\text { Dimungkinkan untuk mulai bekerja } \\
\text { dengan geng atau kelompok. }\end{array}$ & $\begin{array}{l}\text { Siswa akan melukiskan teman dan } \\
\text { karyanya. Guru dapat menggunakan } \\
\text { persetujuan kawannya } \\
\text { memodifikasi perilakunya. }\end{array}$ \\
\hline 7 & Menyenangi buku komik. & $\begin{array}{l}\text { Siswa akan berkreasi karakter komik dan } \\
\text { superhero. }\end{array}$ \\
\hline 8 & $\begin{array}{l}\text { Pertumbuhan dan kemampuan kritik, } \\
\text { evaluasi diri, dan mengevaluasi yang } \\
\text { lain. }\end{array}$ & $\begin{array}{l}\text { Siswa akan menggunakan tujuan } \\
\text { pembelajaran untuk mengevaluasi karya } \\
\text { mereka. }\end{array}$ \\
\hline 9 & $\begin{array}{l}\text { Kemampuan untuk berkonsentrasi } \\
\text { pada masa ini lebih lama. }\end{array}$ & $\begin{array}{l}\text { Mengerjakan proyek memmungkinkan } \\
\text { lebih lama jika tujuan baru diketahui. }\end{array}$ \\
\hline 10 & $\begin{array}{l}\text { Mengembangkan minat dalam } \\
\text { berpergian (travel). }\end{array}$ & $\begin{array}{l}\text { Siswa akan mendeskripsikan bagaimana } \\
\text { hubungan cerita berkarya dengan budaya. }\end{array}$ \\
\hline 11 & $\begin{array}{l}\text { Proses kehidupan tumbuhan dan } \\
\text { binatang menarik bagi mereka. }\end{array}$ & $\begin{array}{l}\text { Siswa akan menggambar dari kehidupan, } \\
\text { membuat model dengan cara mengisi } \\
\text { kulit binatang, gambar flora dan fauna, } \\
\text { dan mendeskripsikan cara mereka } \\
\text { menggambar secara khusus mengenai } \\
\text { tanaman dan binatang. }\end{array}$ \\
\hline 12 & Mengembangkan perasaan humor. & $\begin{array}{l}\text { Siswa akan mendiskusikan isu keindahan } \\
\text { yang muncul dari gambar kartun. }\end{array}$ \\
\hline 13 & Memiliki kegemaran mengumpulkan. & $\begin{array}{l}\text { Siswa akan mendiskusikan karya yang } \\
\text { dikumpulkannya dalam kegiatan kritik. }\end{array}$ \\
\hline
\end{tabular}

\subsection{Relevansi Materi Pokok SBdP MI/SD}

Relevansi materi mencakup struktur kurikulum SBdP MI/SD terkini, kesesuaian karakteristik perkembangan perserta didik MI/SD, higher order thinking skill (HOTS), 4C (creative, critical thinking, communicative, dan colaborative), literasi budaya dan kewargaan, dan pendidikan karakter. Pertama, struktur kurikulum SBdP MI/SD terkini. Berikut kategori alokasi waktu per mata pelajaran pada pembelajaran tematik. 
Tabel 3. Kategori Alokasi Waktu Per Mata Pelajaran pada Pembelajaran Tematik

No.

Mata Pelajaran

Alokasi Waktu Belajar Per Minggu

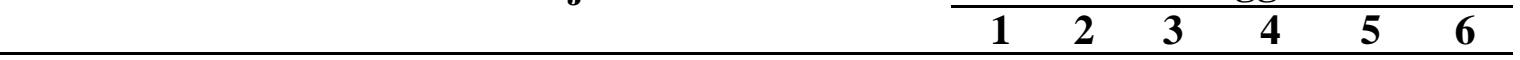

\section{Kelompok A}

\begin{tabular}{llcccccc}
\hline 1 & Pendidikan agama dan budi pekerti & 4 & 4 & 4 & 4 & 4 & 4 \\
\hline 2 & Pendidikan Pancasila dan kewarganegaraan & 5 & 6 & 6 & 4 & 4 & 4 \\
\hline 3 & Bahasa Indonesia & 8 & 8 & 10 & 7 & 7 & 7 \\
\hline 4 & Matematika & 5 & 6 & 6 & 6 & 6 & 6 \\
\hline 5 & Ilmu pengetahuan alam & - & - & - & 3 & 3 & 3 \\
\hline 6 & Ilmu pengetahuan sosial & - & - & - & 3 & 3 & 3 \\
\hline \multicolumn{1}{c}{ Kelompok B } & & & & & \\
\hline $\begin{array}{l}\text { Seni budaya dan prakarya (termasuk muatan } \\
\text { lokal) }\end{array}$ & 4 & 4 & 4 & 6 & 6 & 6 \\
\hline 2 & $\begin{array}{l}\text { Pendidikan jasmani, olahraga, dan kesehatan } \\
\text { (termasuk muatan lokal) }\end{array}$ & 4 & 4 & 4 & 3 & 3 & 3 \\
\hline & Alokasi Waktu Per Minggu & 30 & 3 & 34 & 36 & 36 & 36 \\
\hline
\end{tabular}

Kelompok A adalah kelompok pelajaran yang kontennya dikembangkan oleh pusat, sedangkan kelompok B adalah mata pelajaran yang kontennya dikembangkan oleh pusat dan dilengkapi dengan konten lokal yang dikembangakan oleh pemerintah daerah. Beban belajar dinyatakan dalam jam belajar setiap minggu untuk masa belajar selama satu semester. Beban belajar untuk MI/SD kelas I, II, dan III masing-masing 30, 32, dan 34, sedangkan kelas IV, V, dan VI adalah 36 jam per minggu. Durasi belajar untuk jenjang MI/SD adalah 35 menit (Kemendikbud, 2014).

Kompetensi inti dan kompetensi dasar pada mata pelajaran SBdP MI/SD kelas III sesuai dengan Permendikbud nomor 24 tahun 2016 tentang kompetensi inti dan kompetensi dasar pelajaran pada kurikulum 2013 pada pendidikan dasar dan pendidikan menengah adalah sebagai berikut:

Tabel 4. Kategori Kompetensi Inti SBdP Kelas III MI/SD

\section{Kompetensi Inti}

1 Menerima, menjalankan, dan menghargai ajaran agama yang dianutnya.

Menunjukkan perilaku jujur, disiplin, tanggung jawab, santun, peduli, percaya diri,

2 dalam berinteraksi dengan keluarga, teman, dan guru, serta tetangga, dan cinta tanah air.

Memahami pengetahuan faktual, konseptual, prosedural, dan metakognitif pada

3 tingkat dasar dengan cara mengamati, menanya, dan mencoba berdasarkan rasa ingin tahu tentang dirinya, makhluk ciptaan Tuhan dan kegiatannya, serta bendabenda yang dijumpa inya di rumah, di sekolah, dan tempat bermain.
Menunjukkan keterampilan berpikir dan bertindak kreatif, produktif, kritis, mandiri, kolaboratif, dan komunikatif. Dalam bahasa yang jelas, sistematis, logis
4 dan kritis, dalam karya yang estetis, dalam gerakan yang mencerminkan anak sehat, dan tindakan yang mencerminkan perilaku anak sesuai dengan tahap perkembangannya.


Tabel 5. Kategori Kompetensi Dasar SBdP Kelas III MI/SD

\section{Kompetensi Dasar}

3.1 Mengetahui unsur-unsur seni rupa dalam karya dekoratif.

3.2 Mengetahui bentuk dan variasi pola irama dalam lagu.

3.3 Mengetahui dinamika gerak tari.

3.4 Mengetahui teknik potong, lipat, dan sambung.

Kompetensi inti dan kompetensi dasar berdasarkan pada lampiran Permendikbud nomor 24 tahun 2016 sudah relevan dengan kompetensi inti dan kompetensi dasar yang digunakan pada buku paket tematik guru dan buku paket tematik siswa kelas III revisi 2018. Kedua, kesesuaian karakteristik perkembangan perserta didik MI/SD. Setiap manusia pasti mengalami perubahan pada dirinya, baik secara fisik maupun secara psikis. Begitu pula dengan anak-anak. Hal ini perlu untuk dipahami para pendidik. Setelah membahas karakteristik pendidikan SBdP MI/SD, penulis akan membahas karakteristik perkembangan siswa.

Karakteristik dan fase perkembangan anak, yaitu masa anak-anak (midle childhood) yang berlangsung antara usia 6-12 tahun. Masa ini sering disebut masa sekolah, yaitu masa matang untuk belajar atau masa matang untuk sekolah. Pada masa ini, mereka menginginkan untuk menguasai kecakapan-kecakapan baru yang dapat diberikan oleh sekolah (Hendriani, 2016: 112). Berdasarkan hasil penelitian, diperoleh beberapa karakteristik perilaku anak pada usia ini berdasarkan jenis kelaminnya, yaitu anak laki-laki lebih banyak melakukan agresivitas, aktivitas, dominasi, dan implusif dalam tingkah lakunya. Mereka memiliki kecakapan mengamati ruang dan pengertian kuantitatif lebih kuat serta lebih baik dibandingkan dengan anak perempuan. Sementara itu, anak perempuan lebih banyak melakukan tingkah laku cemas, tetapi mereka mempunyai kecakapan verbal yang lebih baik daripada anak laki-laki.

Pada usia 6-12 tahun ini, objek gambar anak laki-laki berbeda dengan anak perempuan. Hal ini ditegaskan oleh Fisher dalam Runitinah (2010: 24), bahwa umumnya anak perempuan akan menggambar pemandangan (landscape) yang dilengkapi dengan binatang, pohon, bunga, bangunan, orang, dan matahari, sedangkan anak laki-laki menggambar suasana perang, mobil, perahu, dan kartun.

Menurut Piaget dalam Jamaris (2013: 26), tahap-tahap perkembangan kognitif anak dibagi menjadi empat yakni anak usia 0-2 tahun beradap pada tahap sensorik motorik, untuk anak usia 2-7 tahun berada pada tahap praoprasional, untuk anak usia 711 tahun berada pada tahap oprasional konkrit, dan anak usia 11 tahun sampai dewasa berada pada tahap oprasional formal.

Siswa kelas 3 umumnya berada pada tingkat oprasional konkrit. Pada tingkat ini, siswa sudah memahami hal-hal yang bersifat konkrit, namun belum dapat menghadapi hal-hal yang bersifat abstrak. Oleh karena itu, buku yang digunakan dalam proses pembelajaran SBdP harus memperhatikan hal-hal tersebut. Karakteristik anak-anak inilah yang perlu mendapat perhatian dalam penyusunan buku ajar. Analisis buku ajar siswa maupun guru berdasarkan karakteristik siswa dapat dilihat pada tabel berikut:

Tabel 6. Kategori Karakteristik Perkembangan Siswa MI/SD kelas III

\begin{tabular}{cll}
\hline No. & \multicolumn{1}{c}{ Aspek } & \multicolumn{1}{c}{ Karakte ris tik } \\
\hline 1 & Bahasa/kosakata & $\begin{array}{l}\text { Kalimat yang digunakan komuikatif dan menggunakan bahasa } \\
\text { yang sederhana dan mudah dipahami. }\end{array}$ \\
\hline 2 & Tata cetak & Bentuk buku persegi panjang yang horizontal dengan ukuran \\
\hline
\end{tabular}




\begin{tabular}{|c|c|c|}
\hline No. & Aspek & Karakte ris tik \\
\hline & & $210-297 \mathrm{~mm}$. \\
\hline \multirow[b]{2}{*}{3} & \multirow[b]{2}{*}{ Produksi isi teks } & Jenis font yang digunakan ialah sans serif dan align left. \\
\hline & & $\begin{array}{l}\text { Perbandingan bacaan dengan ilustrasi gambar adalah } \\
40 \%: 60 \% \text {. }\end{array}$ \\
\hline \multirow{4}{*}{4} & \multirow{4}{*}{ Ilustrasi gambar } & $\begin{array}{l}\text { Materi disertai gambar, sehingga memancing motivasi belajar } \\
\text { anak. }\end{array}$ \\
\hline & & $\begin{array}{l}\text { Ilustrasi gambar sampul sudah mewakili tema yang akan } \\
\text { dibahas dan sesuai untuk disajikan pada anak-anak. }\end{array}$ \\
\hline & & Penyajian gambar yaitu iconic. \\
\hline & & $\begin{array}{l}\text { Dicetak dikertas putih, sehingga memberikan efek visual yang } \\
\text { menarik }\end{array}$ \\
\hline 5 & Isi dan konsep & Teks disajikan dari konkret ke abstrak. \\
\hline
\end{tabular}

Ketiga, higher order thinking skill (HOTS). Saat ini banyak sekali permasalahan yang berkembang dalam kehidupan, diantaranya permasalahan tersebut muncul karena adanya perbedaan antara kebutuhan dan solusi-solusi yang ditawarkan. Solusi yang ditawarkan tidak cukup untuk mengatasi segala permasalahan yang tengah berkembang di masyarakat saat ini. Oleh karena itu, diperlukan keterampilan higher order thinking skill (HOTS), yakni keterampilan untuk berpikir tingkat tinggi.

Keterampilan berpikir tingkat tinggi (higher order thinking skills) berkaitan dengan keterampilan menyelesaikan permasalahan, berpikir kritis, dan berpikir kreatif (Sani, 2019: 90). HOTS berbeda dengan HOT (high order thinking). Jika mengacu pada taksonomi Bloom yang telah direvisi, berpikir tingkat tinggi (HOT) berkaitan dengan kognitif dalam menganalis, mengevaluasi, dan mengkreasi.

Relevansi materi pokok SBdP kelas III buku guru dan buku siswa dengan HOTS (higher order thinking skill) dapat dilihat pada gambar berikut:

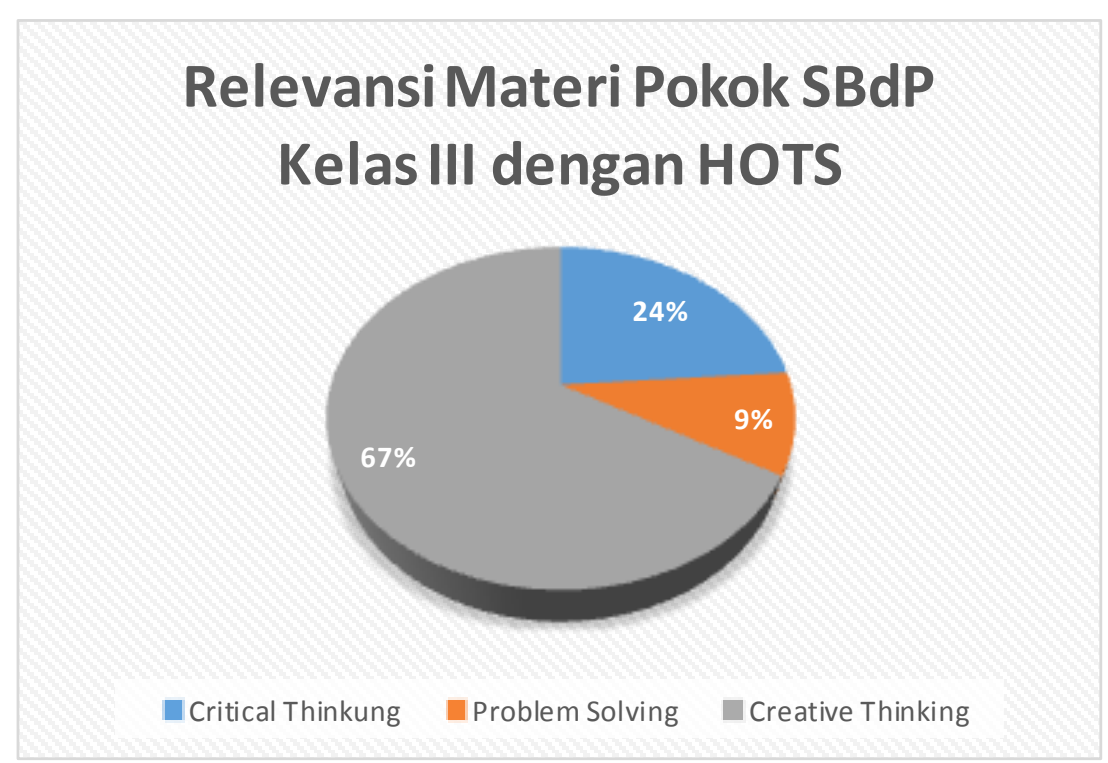

Gambar 2. Diagram Lingkaran Kategori Relevansi Materi Pokok SBdP Kelas III dengan HOTS 
Berdasarkan gambar 2, diperoleh bahwa critical thinking sebesar $24 \%$, problem solving sebesar 9\%, dan creative thinking sebesar 67\%. Materi pokok SBdP kelas III sudah mulai memasukkan soal yang mengarah kepada kemampuan berpikir tingkat tinggi atau yang biasa disebut dengan HOTS (higher order thinking skill), namun dengan persentase yang masih rendah yakni 33\%, sedangkan $67 \%$ sisanya masih mengarah kepada soal LOTS (low order thinking skill).

Keempat yaitu 4C (creative, critical thinking, communicative, dan colaborative). Pembelajaran abad 21 dituntut berbasis teknologi untuk menyeimbangkan tuntutan zaman era milinea dengan tujuan, nantinya siswa terbiasa dengan kecakapan hidup pada abad 21. Menurut Baswedan dalam Sugiyarti, Arif, \& Mursalin, (2018: 440), kecakapan tersebut meliputi: (1) critical thinking (berpikir kritis) yaitu kemampuan siswa dalam berpikir kritis berupa bernalar, mengungkapkan, menganalisis, dan menyelesaikan masalah. Di era reformasi critical thinking digunakan untuk memfilter paham radikal yang tidak masuk akal, (2) communication (komunikasi) yaitu kemampuan dalam menyampaikan gagasan baik tertulis maupun secara lisan, (3) collaboration (kolaborasi) yaitu kemampuan bekerja sama sebagai tim yang solid dalam mengatasi suatu permasalahan, dan (4) creativity (kreatifitas) yaitu kemampuan untuk menghasilkan sesuatu yang baru yang belum pernah dikenal sebelumnya untuk solusi permasalahan yang baru.

Relevansi materi pokok SBdP kelas III buku guru dan buku siswa dengan 4C (critical thinking, communication, callaboration, dan creativity) dapat dilihat pada gambar berikut:

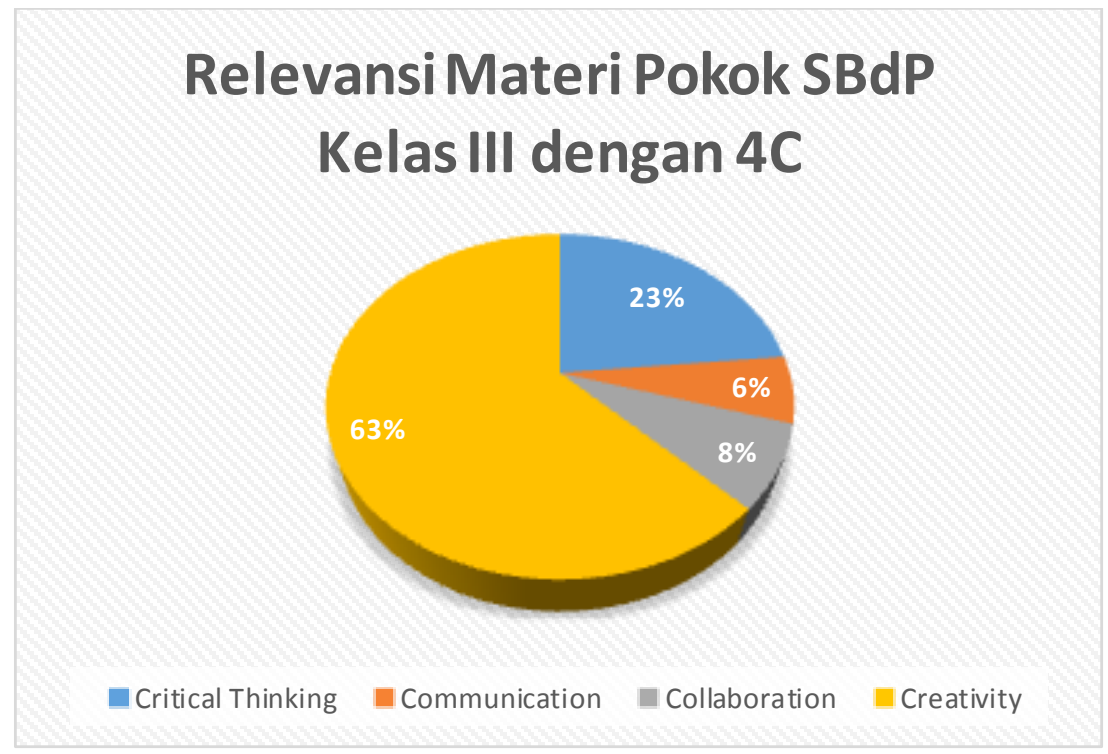

Gambar 3. Diagram Lingkaran Kategori Relevansi Materi Pokok SBdP Kelas III dengan $4 \mathrm{C}$

Berdasarkan gambar 3, diperoleh bahwa critical thinking sebesar 23\%, communication sebesar $6 \%$, collaboration sebesar $8 \%$, dan creativity sebesar $63 \%$. Materi pokok SBdP kelas III sudah mulai mengarah pada pembelajaran abad 21 dengan memasukkan semua komponen 4C yang didominasi oleh keterampilan creativity, karena dalam mata pelajaran SBdP bertujuan agar siswa bisa mengembangkan kreativitasnya dalam berkreasi dan berapresiasi terhadap seni. 
Kelima yaitu literasi budaya dan kewargaan. Literasi budaya merupakan kemampuan untuk bersikap dan memahami kebudayaan yang ada di Indonesia untuk menunjukkan identitas bangsa, sedangkan literasi kewargaan adalah kemampuan untuk memahami hak dan kewajiaban yang harus dipatuhi sebagai warga Negara. Jadi literasi budaya dan kewargaan merupakan kemampuan individu dan masyarakat dalam bersikap terhadap lingkungan sosialnya sebagai bagian dari suatu budaya dan bangsa (Gerakan Literasi Nasional, 2019).

Berdasarkan hal tersebut, literasi budaya dan kewargaan dapat dikembangkan di pembelajaran SBdP, contohnya memperagakan gerak tari dengan diiringi lagu daerah. Hal tersebut dapat memberikan pengetahuan dasar bagi siswa di bidang literasi budaya dan kewargaan.

Tabel 7. Kategori Data Literasi Budaya dan Kewargaan Kelas III Tematik Kurikulum 2013 Revisi 2018

\begin{tabular}{ccclcc}
\hline Tema & Sub Tema & Pembelajaran & \multicolumn{1}{c}{ Indikator } & HIm BG & HIm BS \\
\hline 4 & 2 & 1 & $\begin{array}{l}\text { Siswa mampu } \\
\text { memperagakan gerak } \\
\text { lemah dan kuat kaki dalam } \\
\text { suatu tarian diiringi lagu } \\
\text { daerah. }\end{array}$ & 63 & $52-55$ \\
\hline 4 & 2 & 3 & $\begin{array}{l}\text { Siswa mampu membentuk } \\
\text { gerakan kaki menjadi gerak } \\
\text { tari diiringi lagu daerah. }\end{array}$ & 75 & $65-66$ \\
\hline
\end{tabular}

Dari tabel 7, dapat disimpulkan bahwa belum semua tema memiliki aspek literasi budaya dan kewargaan, menurut analisa penulis ada satu tema yang menerapkan literasi budaya dan kewargaan, yaitu tema 4. Sehingga, dapat dikatakan bahwa belum adanya upaya untuk menguatkan atau menumbuhkan literasi budaya dan kewargaan pada buku tematik kurikulum 2013 revisi 2018 pada kelas III MI/SD.

Keenam yaitu pendidikan karakter. Pendidikan karakter adalah suatu sistem untuk menanamkan nilai-nilai karakter kepada warga sekolah (Hasanah, 2017: 44). Selain itu pendidikan karakter juga diartikan sabagai upaya yang dilakukan untuk menanamkan kecerdasan dalam berfikir, bersikap, dan berperilaku yang sesuai dengan nilai-nilai luhur yang menjadi jati dirinya, diwujudkan dalam interaksi dengan Tuhannya, diri sendiri, masyarakat, dan lingkungannya (Rosala, 2016: 16-25). Sebagian besar nilai-nilai karakter telah diterapkan di dalam buku ajar tematik kelas III. Pendidikan karakter di dalam materi pembelajaran SBdP dapat dikembangkan lagi oleh guru dengan menerapkan nilai-nilai pendidikan karakter.

Tabel 8. Kategori Implementasi Pendidkan Karakter pada Materi Pokok SBdP dalam Buku Paket Tematik Terpadu

\begin{tabular}{clccc}
\hline No & Nilai Karakter & Tema & Subtema & Pe mbelajaran \\
\hline 1 & Religius & - & - & - \\
\hline 2 & Jujur & 4 & 1 & 1 \\
\hline 3 & Toleransi & 5 & 3 & 1 \\
\hline 4 & Disiplin & 4 & 2 & 3 \\
\hline 5 & Kerja keras & 1 & 2 & 1 \\
\hline 6 & Kreatif & 1 & 1 & 3 \\
\hline \hline
\end{tabular}

AULADUNA: Jurnal Pendidikan Dasar Islam 


\begin{tabular}{|c|c|c|c|c|}
\hline No & Nilai Karakter & Tema & Subtema & Pembelajaran \\
\hline & & 1 & 4 & 3 \\
\hline & & 2 & 4 & 3 \\
\hline & & 4 & 4 & 3 \\
\hline & & 6 & 4 & 3 \\
\hline 7 & Mandiri & 3 & 4 & 3 \\
\hline 8 & Demokratis & - & - & - \\
\hline 9 & Rasa ingin tahu & 4 & 3 & 1 \\
\hline 10 & Semangat kebangsaan & 8 & 1 & 1 \\
\hline \multirow{3}{*}{11} & \multirow{3}{*}{ Cinta tanah air } & 2 & 3 & 3 \\
\hline & & 4 & 2 & 1 \\
\hline & & 5 & 3 & 3 \\
\hline 12 & Menghargai prestasi & - & - & - \\
\hline \multirow{2}{*}{13} & \multirow{2}{*}{ Persahabatan/komunikatif } & 1 & 2 & 1 \\
\hline & & 4 & 3 & 3 \\
\hline 14 & Cinta damai & - & - & - \\
\hline 15 & Gemar membaca & - & - & - \\
\hline \multirow{2}{*}{16} & \multirow{2}{*}{ Peduli lingkungan } & 2 & 1 & 1 \\
\hline & & 7 & 1 & 1 \\
\hline 17 & Peduli sosial & 5 & 3 & 1 \\
\hline 18 & Tanggung jawab & - & - & - \\
\hline
\end{tabular}

\subsection{Inovasi Materi Pokok SBdP MI/SD}

Berdasarkan berbagai permasalahan yang telah disebutkan dan hasil analisis peneliti terhadap materi pokok SBdP dalam buku guru dan buku siswa kelas III kurikulum 2013 revisi 2018, perlu diberikan suatu inovasi agar pembelajaran SBdP lebih bermakna, diantaranya menggunakan multimedia interaktif. Multimedia interaktif merupakan multimedia yang dilengkapi dengan alat pengontrol yang dapat dioperasikan agar mampu melakukan instruksi balik kepada pengguna agar melakukan suatu aktivitas (Muin, 2017: 133-135). Multimedia interaktif juga disebut sebagai kombinasi dari berbagai media (audio, grafik, teks, video, dan gambar) yang digunakan untuk mengendalikan perintah (Prastowo, 2012: 329).

Bahan ajar yang dikembangkan memiliki manfaat yang banyak, seperti ditemukannya bahan ajar yang sesuai dengan kebutuhan kurikulum, tidak hanya bergantung pada buku teks, bahan ajar lebih komprehensif, menambah keilmuan, mampu membangun komunikasi yang efektif, kegiatan proses pembelajaran lebih menarik, siswa lebih memiliki kesempatan untuk mengeksplor pengetahuan mereka, dan siswa mendapat kemudahan dalam mempelajari materi (Prastowo, 2015: 197).

\section{Simpulan}

Adapun kesimpulan dari penelitian ini, yaitu: (1) semua materi telah merujuk kepada standar isi Permendikbud nomor 21 tahun 2016, maka buku bahan ajar tematik (buku guru dan buku siswa) telah relevan atau telah memenuhi ruang lingkup materi yang tercantum dalam Permendikbud nomor 21 tahun 2016 di antaranya adalah kreasi dan apresiasi karya seni rupa, kreasi/rekreasi dan apresiasi karya seni musik, kreasi/rekreasi dan apresiasi karya seni tari, serta apresiasi dan kreasi prakarya. Kompetensi dari beberapa materi pokok SBdP MI/SD yaitu kompetensi sikap, 
kompetensi pengetahuan, dan kompetensi keterampilan. Secara umum, buku ajar siswa kelas III MI/SD, baik buku guru dan buku siswa sudah relevan dengan ruang lingkup SBdP MI/SD, (2) karakteristik materi pokok SBdP MI/SD yaitu mencakup karakteristik dilihat dari aspek materi pokok dan karakteristik perkembangan serta implikasinya dengan pengajaran seni, (3) relevansi materi pokok SBdP MI/SD, meliputi struktur kurikulum SBdP MI/SD, karakteristik perkembangan siswa, dan HOTS meliputi (critical thinking: 24\%, problem solving: 9\%, dan creative thinking: 67\%) dengan persentase yang masih rendah yakni $33 \%$ dan $67 \%$ sisanya masih mengarah kepada soal LOTS (Low Order Thinking Skill), 4C (Critical Thinking: 23\%, Communication: 6\%, Collaboration: 8\%, dan Creativity: 63\%), literasi budaya dan kewargaan, dan pendidikan karakter, dan (4) inovasi materi pokok SBdP MI/SD dengan menggunakan multimedia interaktif.

\section{Daftar Pustaka}

Gerakan Literasi Nasional. (2019). Materi Literasi Budaya dan Kewargaan. Jakarta: Kemendikbud.

Hasanah, A. (2017). Pendidikan Karakter Berperspektif Islam. Bandung: Penerbit Insan Komunika.

Hendriani, D. (2016). Pengembangan Seni Budaya dan Keterampilan. Yogyakarta: Penerbit Ombak.

Jamaris, M. (2013). Orientasi Baru dalam Psikologi Pendidikan. Bogor: Ghalia Indonesia.

Kemendikbud. (2014). Permendikbud No. 57 Tahun 2014 Kurikulum 2013 Sekolah Dasar/Madrasah Ibtidaiyah. Jakarta: Kemendikbud.

Kemendikbud. (2016a). Permendikbud No. 21 Tahun 2016 tentang Standar Isi Pendidikan Dasar dan Menengah. Jakarta: Kemendikbud.

Kemendikbud. (2016b). Permendikbud No. 24 Tahun 2016 tentang Kompetensi Inti dan Kompetensi Dasar Pelajaran pada Kurikulum 2013 pada Pendidikan Dasar dan Pendidikan Menengah. Jakarta: Kemendikbud.

Mislia, T. S., Indartono, S., \& Mallisa, V. (2018). Improving Critical Thinking among Junior High School Students through Assessment of Higher-Level Thinking Skills. In Advances Social Science, Education and Humanities Research: International Conference on Social Science and Character Educations (ICoSSCE 2018) and International Conference on Social Studies, Moral, and Character Education (ICSMC 2018) (Vol. 323, pp. 1-8). Retrieved from https://download.atlantis-press.com/artic le/125910020.pdf

Muin, A. (2017). Keterampilan Berbasis Multimedia Interaktif pada Pembelajaran Seni Budaya di Sekolah Dasar. Jurnal Penelitian Pendidikan INSANI, 20(2), 133135. Retrieved from https://ojs.unm.ac.id/Insani/article/view/4821

Mulyani, N. (2016). Pendidikan Seni Tari Anak Usia Dini. Yogyakarta: Gava Media.

Prastowo, A. (2012). Pengetahuan Kreatif Membuat Bahan Ajar Inovatif. Yogyakarta: Diva Press.

Prastowo, A. (2015). Menyusun Rencana Pelaksanaan Pembelajaran Tematik Terapadu. Jakarta: Prenadamedia Group.

Rosala, D. (2016). Pembelajaran Seni Budaya Berbasis Kearifan Lokal dalam Upaya Membangun Pendidikan Karakter Siswa di Sekolah Dasar. RITME, 2(1), 16-25. Retrieved from https:/ejournal.upi.edu/index.php/ritme/artic le/view/5078

Runitinah. (2010). Peningkatan Kreativitas Menggambar melalui Pembelajaran 
Contextual Teaching and Learning pada Siswa Kelas III SDN Jelok Purworejo Tahun Pelajaran 2009/2010. Universitas Sebelas Maret. Retrieved from https://digilib.uns.ac.id/dokumen/download/22947/NDgyMjM=/Peningkatan-Kr eativitas-Menggambar-Melalui-Pembelajaran-Contextual-Teaching-And-Learni ng-pada-Siswa-Kelas-III-Sd-N-Jelok-Purworejo-Tahun-Pelajaran-2009-2010-ab strak.pdf

Sani, R. A. (2019). Pembelajaran Berbasis HOTS. Tangerang: Tira Smart.

Snyder, J. J., \& Wiles, J. R. (2015). Peer Led Team Learning in Introductory Biology: Effects on Peer Leader Critical Thinking Skills. PLoS ONE, 10(1), 1-18. https://doi.org/10.1371/journal.pone.0115084

Sugiyarti, L., Arif, A., \& Mursalin. (2018). Pembelajaran Abad 21 di SD. In Prosiding Seminar dan Diskusi Nasional Pendidikan Dasar 2018 dengan Tema "MenyonsongTransformasi Pendidikan Abad 21" (pp. 439-444). Retrieved from http://journal.unj.ac.id/unj/index.php/ps dpd/artic le/download/10184/6600/

Sutiyono. (2010). Pribumisasi Islam melalui Seni Budaya Jawa. Yogyakarta: Insan Persada.

Yusuf, S., \& Hayat, B. (2010). Bencmark Internasional Mutu Pendidikan. Jakarta: Bumi Aksara. 